\title{
FOREST TYPE MAPPING OF BIDAR FOREST DIVISION, KARNATAKA USING GEOINFORMATICS TECHNIQUES
}

\author{
Shashikant.R.Mise ${ }^{1}$ Ganesh $^{2}$ \\ ${ }^{1}$ Professor, Department of Civil Engineering, ${ }^{2}$ M.Tech Scholar, Department of Environmental Engineering, \\ PDA College of Engineering, Gulbarga \\ srmise45@yahoo.com,ganeshn870@gmail.com
}

\begin{abstract}
The study demonstrate the potentiality of satellite remote sensing technique for the generation of baseline information on forest types including tree plantation details in Bidar forest division, Karnataka covering an area of 5814.60Sq.Kms. The Total Area of Bidar forest division is 5814Sq.Kms analysis of the satellite data in the study area reveals that about $84 \%$ of the total area is Covered by crop land, $1.778 \%$ of the area is covered by dry deciduous forest, $1.38 \%$ of mixed plantation, which is very threatening to the environmental stability of the forest, future plantation site has been mapped. With the use of latest Geo-informatics technology proper and exact condition of the trees can be observed and necessary precautions can be taken for future plantation works in an appropriate manner
\end{abstract}

Keywords:-RS, GIS, GPS, Forest Type, Tree Plantation

\section{INTRODUCTION}

Forest is one of the most magnificent expressions of nature on earth .It is an important renewable natural resource and benefits from it are immense, mainly timber and non-timber forest products. It has been an important source of subsistence, employment, revenue and raw materials to various industries. Forest plays an important role in the issues related to green house gases and climate change which are strongly linked to the maintenance of ecological balance, biological diversity, environmental stability, soil and water conservation etc

The main objectives of mapping of the existing forest type and plantation works carried out in Bidar forest division, arnataka. To prepare various forest type map in Bidar forest division using PAN+LISS III data.

Archana et al, (Jan. 2013) had carried out there research work on "Forest Resource Mapping In Pinjore Block, Haryana, Using Geoinformatics Techniques" and said that Forests resources, The analysis of the satellite data also reveals that an area of $18.33 \mathrm{sq} \mathrm{km}(6.36 \%)$ of TOF were present in Pinjore block ${ }^{[1]}$.

M. Kardos(2013) had carried out his research work on "Method Of Digital Photogrammetry in forest management in Slovakia" and said that The practical aspect of utilization of digital photogrammetry methods and their products in Slovak forestry is presented. We deal with the comparison of various data obtained by digital cameras, their accuracy, utilization and effectiveness for mapping ${ }^{[2]}$
Muhammad Asim Rizwan (Dec,2011) had carried his research work on "Forest Mapping by using RS and GIS Techniques" and said that forest have important and vital global ecological as well as socio-economic resources and they require a sustainable management. The aim of this study has, to map the existing forest, to identify unutilized land, to develop a plan to increase the existing forest coverage and carry out the related analysis. ${ }^{[3]}$

\subsection{Scope of the Study:}

The scope of interest in this present study is to use the GIS technologies for the forest management of Bidar division, Karnataka. As the GIS facility was available locally it was convenient to carry out the project work. The interest to choose this particular topic is due to the reason that as per the collected literature so, far the present study is not carried out on forest management in Bidar division using RS and GIS technologies.

\section{METHODOLOGY}

The following methodology has been adopted for the current study and shown in Figure1

Image Processing: Initially the satellite imageries mentioned in the figure above were subjected to radiometric and geometric corrections to get a clear image in real world coordinates.

Geo - referencing: Geo - referencing refers to the process of assigning map coordinates to image data. The image data may 
already be projected onto the desired plane, but not yet referenced to the proper coordinate system. Geo - referencing, by itself, involves changing only the map coordinate information in the image file. The grid of the image does not change.

Mosaic king: The project area pertaining to this project often spanned several image files. Hence, it was necessary to combine the images to create one large file. This technique is called mosaic king.

Sub setting: Sub setting refers to breaking out a portion of a large file into one or more smaller files. At times, image files contained area much larger than a particular project area. In these cases, it was helpful to reduce the size of the image file to include only the Area Of Interest (AOI). This is not only eliminated the extraneous data in the file, but it accelerated the processing due to the smaller amount of data to process. This was important even more because the project involved multiband data.

\section{RESULT AND DISCUSSIONS}

The studies depict the application of remote sensing techniques for the mapping of plantation works and forest type in Bidar, Karnataka. Here Humnbad range is major portion of forest cover in the division. There is variety of trees found in the Bidar forest division the total forest cover occupies 5814 Sq.Kms.

\subsection{Forest Type Mapping}

The forest type map has been generated to show the land area used within the forest division as shown in Figure 1 and the spatial distributions under forest category were shown in Table. 1 and shown in pie chart

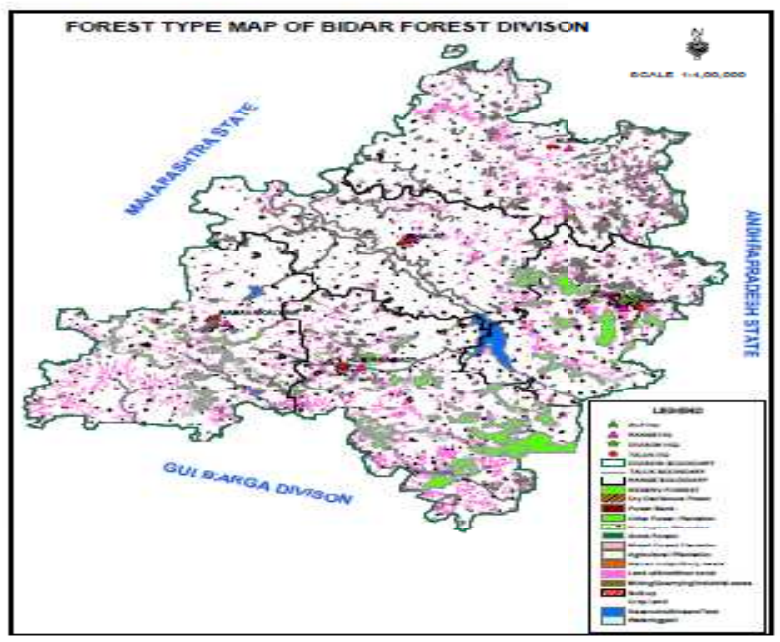

Fig1 forest type map of Bidar forest division:
The Total Area of Bidar forest division is 5814Sq.Kms analysis of the satellite data in the study area reveals that about $84 \%$ of the total area is covered by crop land, $1.778 \%$ of the area is covered by dry deciduous forest, $1.38 \%$ of mixed plantation, which is very threatening to the environmental stability of the forest. Figure No 2.

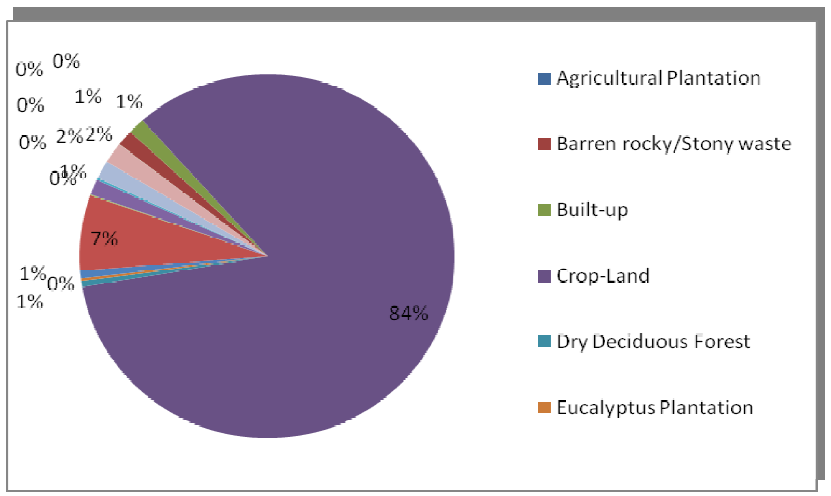

Fig2: Pie Chart showing percentage distribution of varoius forest

\subsection{Plantation Work Maps in Bidar Forest Division}

By using the data obtained from the forest department and interpreting with the GPS values obtained for ground truth verification, maps for plantation raised during 2011-12 as shown in Figure No 3 and the plantation details of 2011-12 has been. Shown and advance work for Future plantation for 2012-13 in Bidar forest division have been generated ads shown in Figure No 4

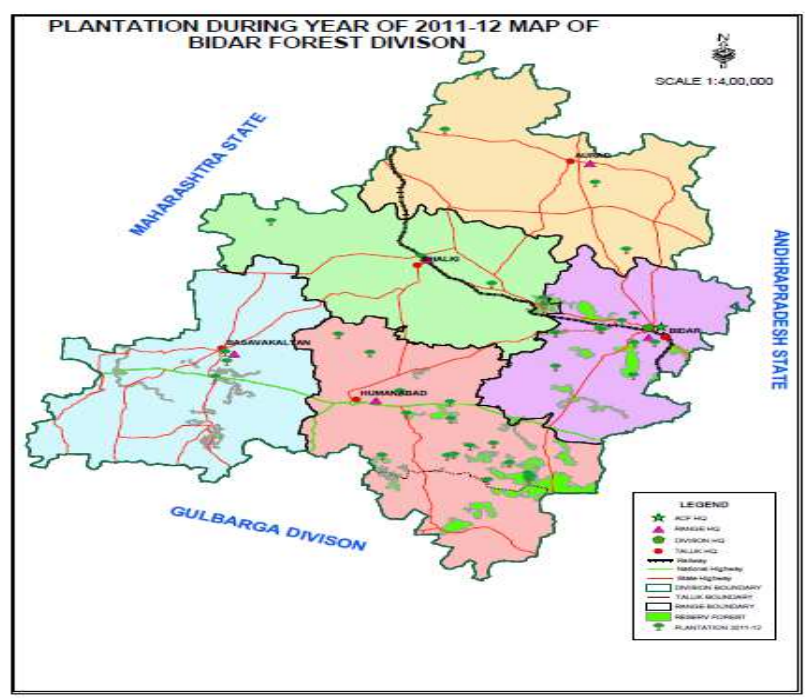

Fig: 3 Plantation work done during 2011-12 in Bidar forest division 


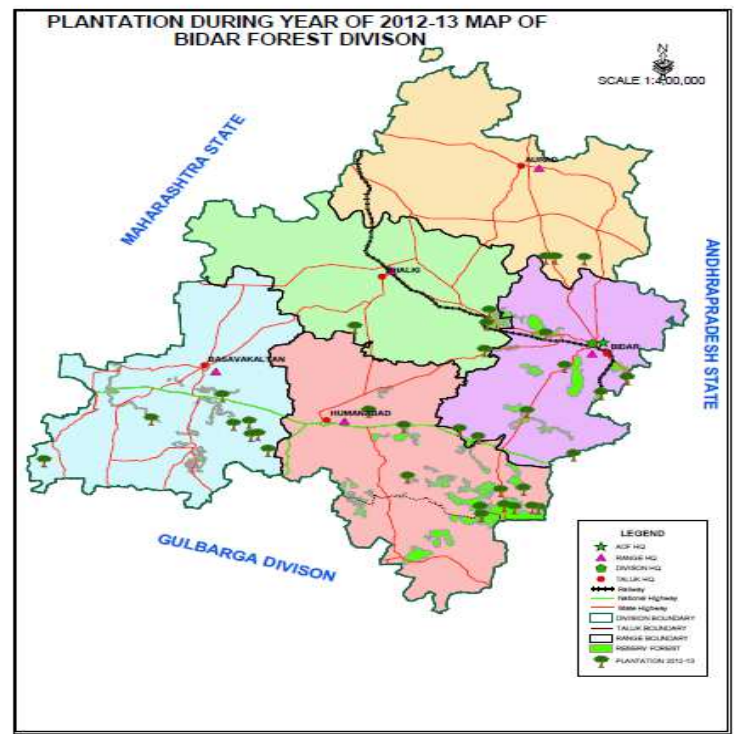

Fig.4 Advance work for future plantation for 2012-13 in Bidar forest division

\subsection{Plantation Works}

Tree planting is the process of transplanting tree seeding, generally for forestry, land reclamination or landscaping purpose. Tree plantation is helpful in creating instant forest, tall tree plantation seeding is good for the environment, stop the encroachment of deserts reclaim land, capture carbon \& reduce-pollution.

\section{CONCLUSIONS}

Based on the results obtained the following conclusions have been made, it is observed that the high resolution LISS-III of IRS-P5 and PAN are merged in identification of types of forest $\&$ its condition in the study area. The total forest cover in Bidar forest division is less than $6.67 \%$ of the total geographical area in the study area which is a serious issue to be considered in order to maintain the environmental stability. During the ground truth collection

Around 12 Sq.Kms area of the total forest division has been planted in the year 2011-2012, major plantation work has been done Humnbad range with plantation covering 8.38 Sq.Kms and least plantation in Aurad range with plantation covering 0.2665 Sq.Kms and around 9.035 Sq.Kms of land has been prepared in advance for future plantation in Bidar forest division. With the use of latest Geo-informatics technology proper and exact condition of the trees can be observed and necessary precautions can be taken for future plantation works in an appropriate manner.

\section{REFERENCES}

[1] Archana, Girish Pajar and Mathi Kumar, K.E. (2013) Forest Resource Mapping In Pinjore Block(Panchkula District),Haryana, Using Geoinfornatics Techniques, International Journal of Advanced Technology and Engineering Research(IJATER) Volume 3,Issue1,Issn No:2250-3536.

[2] M.Kordas: Method Of Digital Photogrammetry In Forest Management Of Slovakia, journal Of Forest Science (2013),59,2013(2):pp54-63.

[3] Mohd Asim Rizwan:Forest. (2011) Mapping Using RS and GIS Techniques, Global Journals Inc (USA), Issue7, Version1.0. 